\title{
Physical properties of raspberry and orange flavoured fruit syrups
}

\author{
ANIKÓ LAMBERT-MERETEI, ESZTER VOZARY and TIMEA KASZAB*
}

Department of Measurements and Process Control, Institute of Food Science and Technology, Hungarian University of Agriculture and Life Sciences, Budapest, Hungary

\section{CONFERENCE FULL PAPER}

Received: June 8, 2021 Accepted: August 24, 2021

Published online: September 9, 2021

(c) 2021 The Author(s)

\begin{abstract}
In the case of fruit syrups, consumers prefer thicker, deep-coloured ones because they remind them of good old homemade ones. Physical properties - as viscosity, colour, refractive index, soluble solid content (SSC), and electrical impedance - of fruit syrups flavoured with raspberry or orange juice were determined. The change of the measured physical properties was determined in three different experiments: 1 . evaluating the effect of sugar and sweetener content 2. evaluating the effect of fruit juice composition and 3. evaluating the effect of sugar content on syrups containing raspberry or orange juice only. Variations in fruit and sugar content had a definite effect on the physical properties of squashes. Viscosity, SSC value, refractive index, and impedance magnitude increased with increasing sugar content and decreased with replacement of sugar with sweeteners although colour characteristics were defined mostly by the colorant added to the squash. Changes in the fruit composition of syrups could influence viscosity, refractive index, and SSC values but the magnitude of impedance showed little changes for all samples. The characteristics of squashes containing only raspberry or orange juice and different sugar content did not follow any trends, which emphasized that additives had a significant effect on the physical properties.
\end{abstract}

\section{KEYWORDS}

fruit syrups, viscosity, colour, refractometry, electrical impedance

\footnotetext{
*Corresponding author. E-mail: Kaszab.Timea@uni-mate.hu
} 


\section{INTRODUCTION}

Decades ago, homemade fruit syrups prepared of raspberry or red currant were exceedingly popular in Hungary. Served with icy water this drink was the children's favourite on sizzling summer days and it is still popular. Luckily, there is a wide range of fruit squashes available in local supermarkets to choose from. Customers usually prefer nice thick syrups with a deep colour and a smell of the fruit it is made of. This kind of drinks belongs to soft drinks in the concentrated drink category, namely squashes and cordials (Ashurst et al., 2017). While homemade squashes have fruits, sugar, and a small amount of tartaric acid as ingredients, storebought products contain less fruit, and more additives to replace the missing fruit content. Many researchers investigated the effect of different additives on quality and on customers' acceptance of fruit juices. Pongsawatamit et al. (2011) analyzed blueberry syrup supplemented with citric acid, sorbic acid, colour, flavor and different amount of xanthan gum. The upward stage of flow curve was detected and apparent viscosity was determined. The syrups with xanthan gum content had higher apparent viscosity. In a study by Ghafari et al. (2013) glucose syrup was substituted with bleached date syrup in non-alcoholic and flavourless beer applying four levels of substitution: $\mathrm{w} / \mathrm{w} 25,50,75$, and 100 percent of glucose syrup. The apparent viscosity and colour were measured. It was found that regarding the results of physical and sensory experiments, the sample with 50 percent date syrup stands to be acceptable having maintained and/or improved the physical characteristics. Al-Dabbas and Al-Qudsi (2012) pasteurized orange nectars measured with the composition of saccharose syrup, citric acid, beta carotene and orange syrup (60\% SS). The samples were sweetened with different ratios of sucrose and sucralose. It was found that the viscosity of nectars decreased when a large proportion of sucrose was replaced with sucralose; furthermore, a decrease in water activities was observed as well, which is proportional to reduction in the viscosity.

The objective of our work was to evaluate the effect of sugar content and fruit composition of fruit juice content on the physical properties - mainly viscosity and colour - of store-bought raspberry and orange flavoured squashes.

\section{MATERIALS AND METHODS}

\section{Materials}

Raspberry and orange flavoured syrups characterized by different sugar, sweetener and fruit contents and fruit composition were purchased from local groceries. All the samples had 33\% fruit juice content in total. Besides, raspberry and orange juice, certain products (R_810_3, R_772_2, O_810_2, O_769_15) contained other fruits, including apple, grape and elderberry. Three sets of experiment were carried out. The used samples and their properties are summarized in Table 1. The orange squashes contained stabilizers (E414, E445, and E1450) except the O_757_33 sample. As for the stabilizers, sample O_600_33 contained xanthan gum, while sample O_769_15 had corn oil as an extra additive.

In the second experimental setup, samples with $79 \pm 2 \mathrm{~g}$ sugar content but different fruit composition in the $33 \mathrm{~m} / \mathrm{m} \%$ fruit juice content were evaluated. The exact fruit composition is summarized in Table 2 . 
Table 1. Major parameters of raspberry and orange syrups used for the experiments

\begin{tabular}{|c|c|c|c|c|c|c|c|}
\hline Sample & $\begin{array}{l}\text { Sugar } \\
\mathrm{g} / 100 \mathrm{~mL}\end{array}$ & $\begin{array}{c}\text { Sweetener } \\
\text { content }\end{array}$ & $\begin{array}{l}\text { Raspberry } \\
\text { content of } \\
\text { juice, } \\
\mathrm{m} / \mathrm{m} \%\end{array}$ & Sample & $\begin{array}{l}\text { Sugar } \\
\mathrm{g} / 100 \mathrm{~mL}\end{array}$ & $\begin{array}{c}\text { Sweetener } \\
\text { content }\end{array}$ & $\begin{array}{c}\text { Orange } \\
\text { content of } \\
\text { juice, } \\
\mathrm{m} / \mathrm{m} \%\end{array}$ \\
\hline \multicolumn{8}{|c|}{ Experiment 1 evaluating the effect of sugar and sweetener content } \\
\hline R_032_1 & 3.2 & YES & 1 & O_020_33 & 2 & YES & 33 \\
\hline$R \_340 \_1$ & 34 & YES & 1 & O_330_8 & 33 & YES & 8 \\
\hline$R \_550 \_3$ & 55 & YES & 3 & O_550_2 & 55 & YES & 2 \\
\hline$R \_600 \_33$ & 60 & NO & 33 & O_600_33 & 60 & NO & 33 \\
\hline$R \_790 \_33$ & 79 & NO & 33 & $0 \_790 \_33$ & 79 & NO & 33 \\
\hline \multicolumn{8}{|c|}{ Experiment 2 evaluating the effect of fruit juice content composition } \\
\hline$R \_772 \_2$ & 77.2 & $\mathrm{NO}$ & 2 & $0 \_810 \_2$ & 81 & NO & 2 \\
\hline$R \_810 \_3$ & 81 & NO & 3 & O_769_15 & 76.9 & NO & 15 \\
\hline$R \_790 \_33$ & 79 & NO & 33 & $0 \_790 \_33$ & 79 & NO & 33 \\
\hline \multicolumn{8}{|c|}{ Experiment 3 evaluating the effect of sugar content on syrups containing raspberry/orange juice only } \\
\hline$R \_575 \_33$ & 57.5 & NO & 33 & O_600_33 & 60 & NO & 33 \\
\hline$R \_600 \_33$ & 60 & NO & 33 & $0 \_740 \_33$ & 74 & NO & 33 \\
\hline R_740_33 & 74 & $\mathrm{NO}$ & 33 & O_757_33 & 75.7 & $\mathrm{NO}$ & 33 \\
\hline$R \_790 \_33$ & 79 & $\mathrm{NO}$ & 33 & O_790_33 & 79 & $\mathrm{NO}$ & 33 \\
\hline
\end{tabular}

Table 2. Fruit juice content of raspberry and orange squashes (Experiment 2)

\begin{tabular}{lcccccc}
\hline Fruit juice & R_772_2 & R_810_3 & R_790_33 & O_810_2 & O_769_15 & O_790_33 \\
\hline Raspberry & $2 \%$ & $3 \%$ & $33 \%$ & - & - & - \\
Orange & - & - & - & $2 \%$ & $15 \%$ & $33 \%$ \\
Apple & $24.5 \%$ & $24.5 \%$ & - & $24.5 \%$ & $18 \%$ & - \\
Grape & $6 \%$ & $5.5 \%$ & - & $6.5 \%$ & - & - \\
Elderberry & $0.5 \%$ & - & - & - & - & - \\
\hline
\end{tabular}

\section{Methods}

The flow curve of all samples was measured with MCR302 modular compact rheometer (Anton Paar, Austria) in coaxial cylindrical geometry (CC27) by Rheo Compass software. The measurement consisted of three stages: increasing shear rate from $0.11 / \mathrm{s}$ to $250 \mathrm{1} / \mathrm{s}$ in $120 \mathrm{~s}$; keeping shear rate constant - $250 \mathrm{1} / \mathrm{s}$ - for $120 \mathrm{~s}$; reducing shear rate from $250 \mathrm{1} / \mathrm{s}$ to $0.1 \mathrm{l} / \mathrm{s}$ in $120 \mathrm{~s}$. Viscosity was determined at $250 \mathrm{1} / \mathrm{s}$ shear rate in the constant stage.

The CIELAB L*, $\mathrm{a}^{*}$ and $\mathrm{b}^{*}$ colour coordinates were measured with ColorLite sph850 (ColorLite, Germany) spectrophotometer (Korzenszky et al., 2020). Abbe refractometer was applied to determine refractive index and soluble solid content (SSC). The flow curve, colour, refractive index and soluble solid content of samples were measured in triplicates at $25 \pm 0.1{ }^{\circ} \mathrm{C}$.

As for the dielectric properties the magnitude $(Z)$ and the phase angle $(\varphi)$ of electrical impedance in frequency range from $30 \mathrm{~Hz}$ up to $1 \mathrm{MHz}$ and from $75 \mathrm{kHz}$ up to $30 \mathrm{MHz}$ were measured with precision LCR meters HP4284A and HP4285A, respectively (Vozáry et al., 2020). Home-made stainless-steel electrodes were inserted into the liquid sample of $15 \mathrm{~mL}$ volume, 
furthermore, the distance between the electrodes was $10.5 \mathrm{~mm}$ and the measuring voltage was $1 \mathrm{~V}$. LabVIEW program was used for collecting measured data and curves were created using Microsoft Excel.

Received viscosity data were analyzed with IBM SPSS Statistics 25.0.2.2 software. Significant difference between the measured groups was determined by one-way analysis of variances (ANOVA) with 95\% confidence level. Tukey HSD test was used after normality and standard deviation homogeneity test.

\section{RESULTS AND DISCUSSION}

As supposed, in Experiment 1 the syrups with higher sugar content had higher viscosity, and the use of sweeteners caused a dramatic drop of viscosity (Fig. 1).

Based on the results of colour measurements (Fig. 2), orange syrups with the highest sugar and orange juice content had a nice, reddish-yellow colour, like the peel of the orange fruit itself. Samples prepared with sweeteners and barely any orange juice had a light yellowish colour and do not really meet the consumers' expectations. In the case of raspberry syrups, the two samples (R_600_33 and R_790_33) containing only raspberry juice had quite different values. Meanwhile, R_790_33 had a warm red colour, R_600_33 was slightly purple. Both samples had anthocyanin as colorant.

Anthocyanins are water soluble dyes found in nature. They are responsible for the colour varieties from red to blue in plants. Changes in $\mathrm{pH}$ value cause the reversible change of anthocyanins' colour which is related to the structural transformations (Torskangerpoll and Andersen, 2005).

Tang et al. (2019) observed the spectral features of anthocyanin solutions in the wavelength range of 400-700 at different $\mathrm{pH}$ values. Increasing the $\mathrm{pH}$ value from 2 to 6 the initial absorption band of $528 \mathrm{~nm}$ was shifted to $551 \mathrm{~nm}$. Increasing the $\mathrm{pH}$ further to 6 , the absorption band became broader and further shifted to $551 \mathrm{~nm}$ which means the colour turns to purple/ violet. In our case, R_790_33 contained citric acid as acidulant and ascorbic acid as antioxidant, while R_600_33 contained only citric acid, thus, the higher pH resulted in a purplish colour.

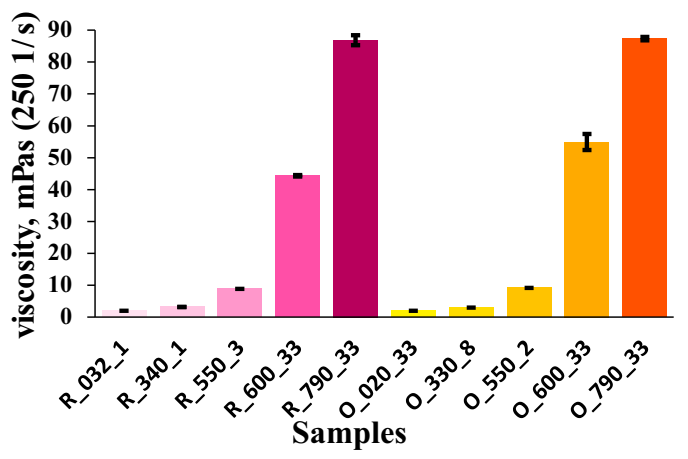

Fig. 1. Viscosity of raspberry and orange syrups characterized by different sugar, sweetener and fruit contents (Experiment 1). Mean value \pm standard deviation at $250 \mathrm{1} / \mathrm{s}$ shear rate 


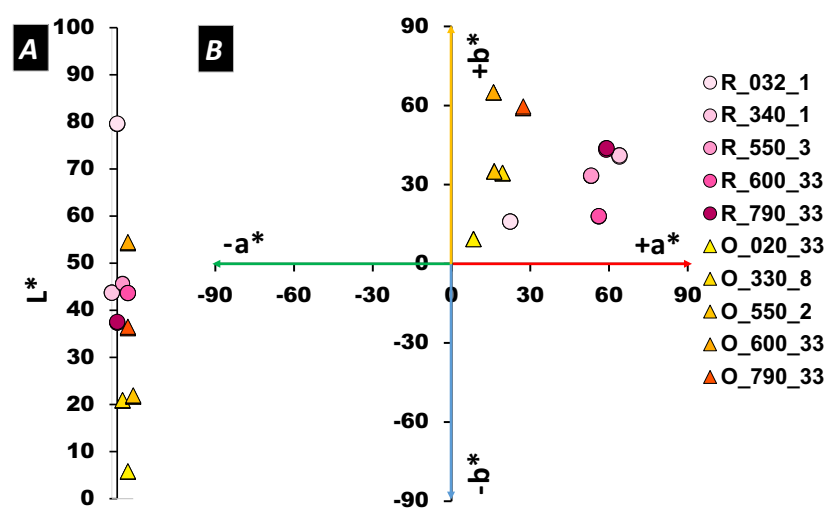

Fig. 2. $\mathrm{L}^{*}(\mathrm{~A})$ and $\mathrm{a}^{*}$ and $\mathrm{b}^{*}$ (B) CIE Lab parameters of raspberry and orange flavoured syrups characterized by different sugar, sweetener and fruit contents (Experiment 1)

During the first experiment, the refractive index and SSC of the tested raspberry and orange syrups changed similarly, as the higher sugar contents increased both values.

The results of dielectric measurements showed that variations in the sugar and sweetener content can influence the electrical characteristics of fruit syrups (Fig. 3). The impedance magnitude increased with increasing sugar content.

During the second experiment, the effect of different fruit compositions on the physical properties of syrups was evaluated. The obtained results showed that the fruit composition as well as the sugar content of the syrups were able to influence the viscosity of the tested products (Fig. 4). In the case of raspberry squashes, viscosity increased with flavour specific fruit content.

Orange syrups have similar characteristics, but they showed a slightly different trend. The sample (O_769_15) containing relatively high orange juice content (15\%) had the lowest viscosity. However, it was the only one which contained maize oil as an additive and this may influence the viscosity, but further investigation is needed.

Results of colour measurements in Experiment 2 did not show real correlation between the fruit content and $L^{*}, a^{*}, b^{*}$ values. All the samples contained colorants, so the colour did not
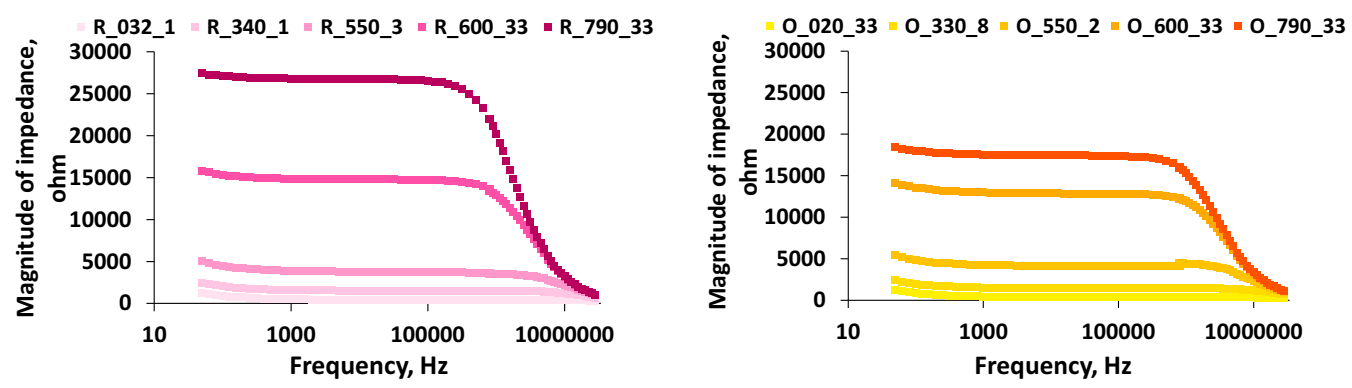

Fig. 3. Impedance magnitudes of raspberry and orange flavoured syrups characterized by different sugar, sweetener and fruit contents (Experiment 1) 


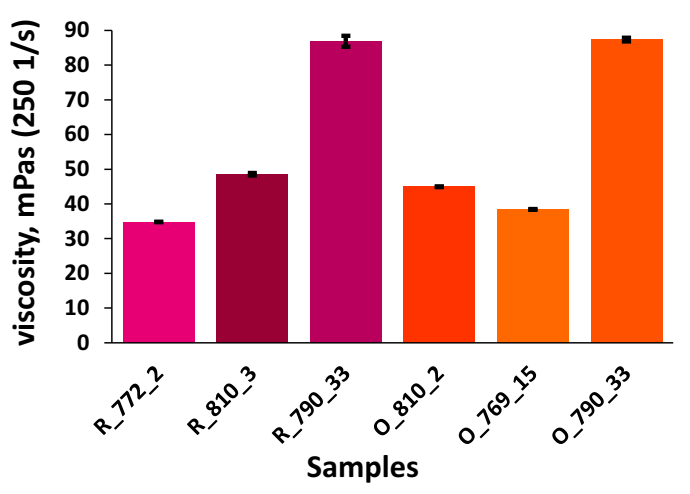

Fig. 4. Viscosity of raspberry and orange flavoured syrups characterized by various fruit compositions

(Experiment 2). Mean value \pm standard deviation at $2501 / \mathrm{s}$ shear rate

represent the fruit content. In the case of orange syrups, the reddish-yellow O_790_33 and O_810_2 samples had similar $\mathrm{a}^{*}$ and $\mathrm{b}^{*}$ values but $\mathrm{O} \_810 \_2$ contained only $2 \%$ orange juice. However, both samples contained carotenes and Beta-apo- $8^{\prime}$-carotenal while the lighter yellow orange sample (O_769_15) with $15 \%$ orange juice contained only carotenes. Raspberry samples differed from each other and all of them contained different colorants. R_790_33 with 33\% raspberry juice contained only anthocyanins and had a red colour like raspberry fruit. Sample R_810_3 containing anthocyanins and sulphite ammonia caramel was represented by a cool red colour. R_772_2 syrup was coloured with black carrot juice, caramel and contained 0.5\% elderberry fruit juice, so its colour moved towards purply pinks.

Refractive index and SSC values showed similar trend to changes in viscosity. Because of nearly the same sugar content of the samples, similar values were expected. However, there were remarkable differences in the parameters. Samples containing only raspberry or orange juice had the highest values for both refractive index and SSC. The magnitude of the electrical impedance depended somewhat on the composition of the fruit; the value of the phase angle remained essentially the same for the different compositions (Fig. 5). This showed that the nature of the electrical conduction did not depend on the fruit composition of the syrup.
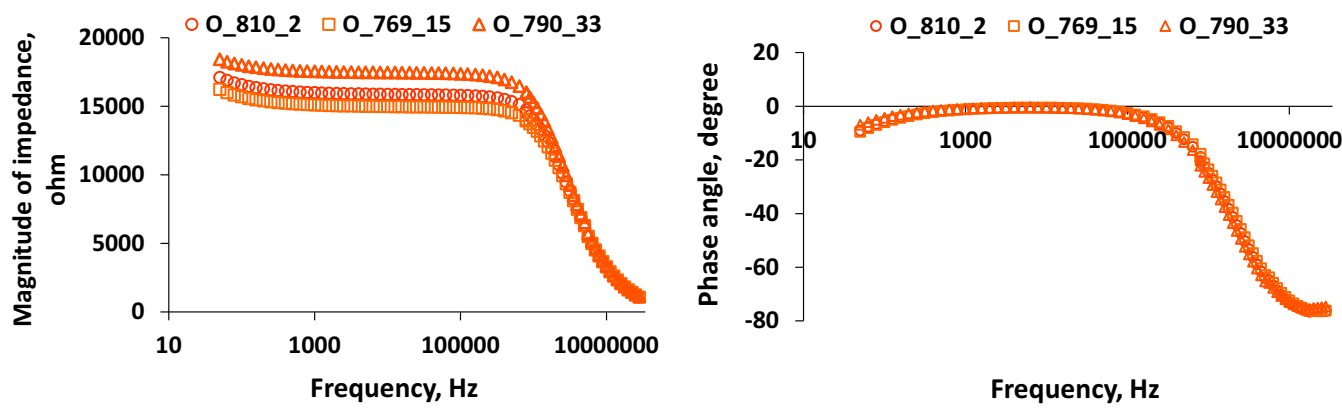

Frequency, $\mathrm{Hz}$

Fig. 5. Impedance magnitude and phase angle of raspberry and orange flavoured syrups characterized by various fruit compositions (Experiment 2) 
To eliminate the effect of sweeteners and different fruit juices, samples made with sugar and $33 \%$ of pure raspberry or pure orange juice were tested in Experiment 3. Samples with $74 \mathrm{~g} /$ $100 \mathrm{~mL}$ sugar content (R_740_33 and O_740_33) had the lowest viscosity both in raspberry and orange flavoured squashes (Fig. 6). Both syrups were procured from the same producer. Sample R-740_33 contained elderberry syrup as colorant, and O_740_33 was the only orange flavoured sample containing ascorbic acid as antioxidant. The sample O_600_33 had slightly higher viscosity than expected presumably because of its xanthan gum content.

All the syrups in this experiment contained 33\% raspberry or orange juice only. Thus, the CIE L*, a*, b* values were similar (Fig. 7).

Raspberry squashes had deep red colour except R_600_33 with slightly higher pH value. Most of raspberry syrups had anthocyanin as colorant. R_740_33 contained elderberry juice instead of anthocyanin. The orange flavoured samples were slightly different. O_790_33 and O_740_33 contained the same colorants namely carotenes and beta-apo-8-carotenal causing

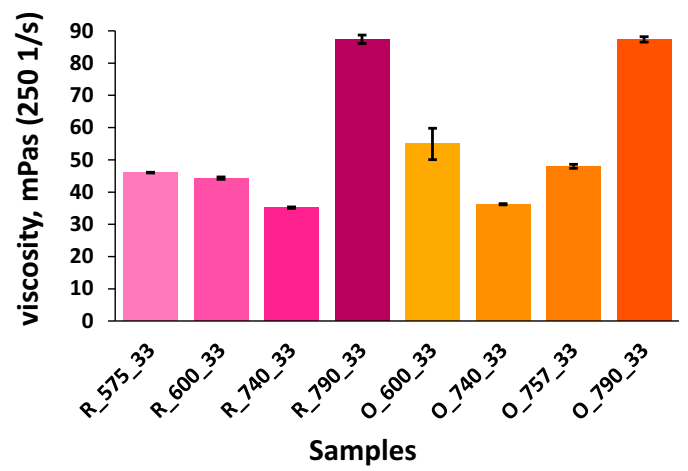

Fig. 6. Viscosity of syrups containing raspberry or orange juice only and characterized by various sugar content (Experiment 3). Mean value \pm standard deviation at $250 \mathrm{l} / \mathrm{s}$ shear rate
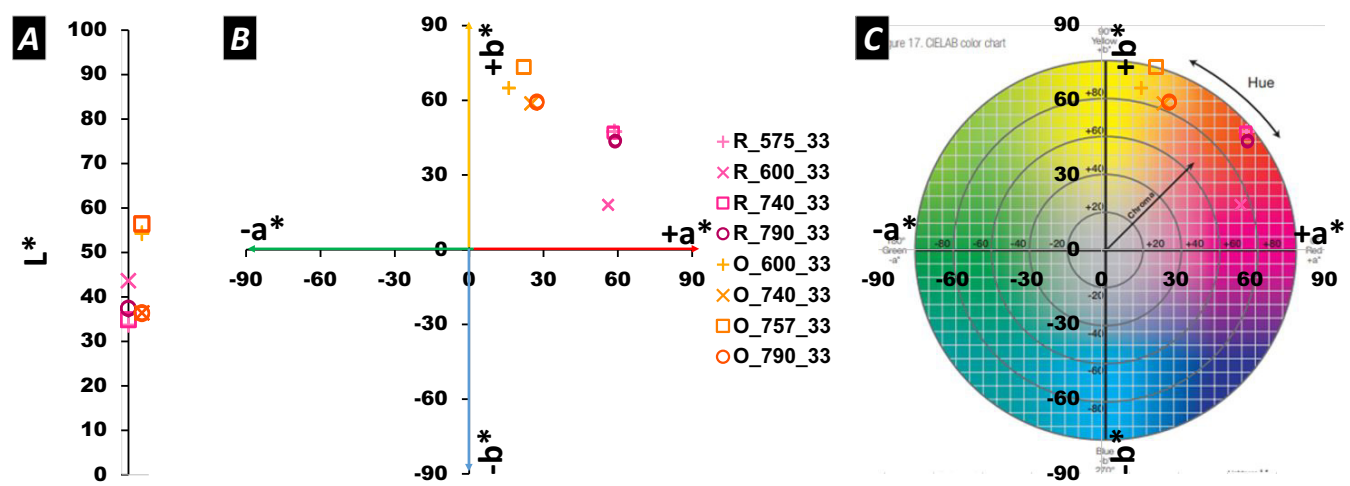

Fig. 7. $\mathrm{L}^{*}(\mathrm{~A})$ and $\mathrm{a}^{*}$ and $\mathrm{b}^{*}$ (B) CIE Lab parameters of raspberry and orange flavoured syrups characterized by different sugar, and same fruit contents (Experiment 3$)$. (C) is the $\left(a^{*}, b^{*}\right)$ coordinate system as (B) with the real colour values 

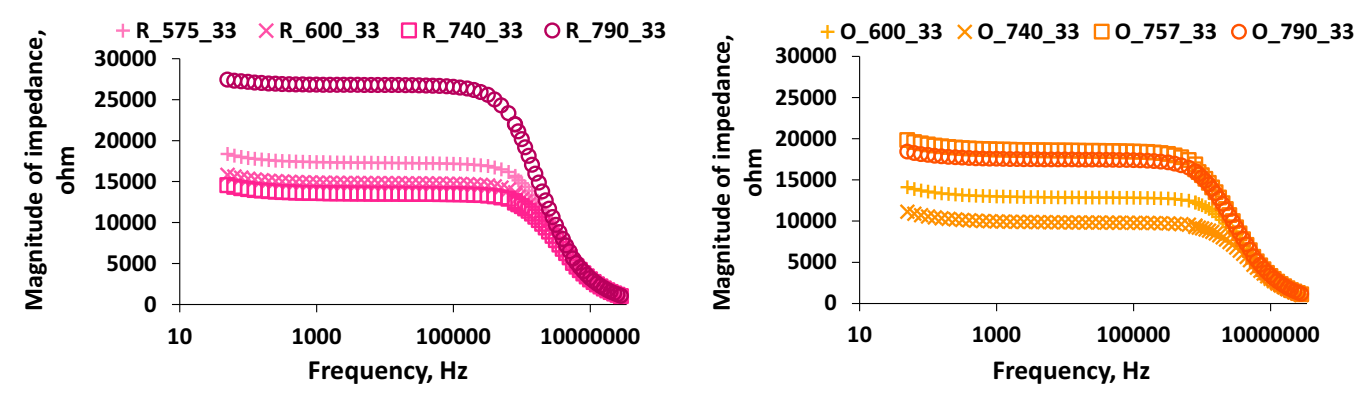

Fig. 8. Impedance magnitudes of syrups containing raspberry or orange juice only and characterized by various sugar content (Experiment 3)

a reddish-yellow colour. O_600_33 with carotenes and sulphite ammonia caramel was brighter yellow. Uniquely sample O_757_33 did not contain any added colorant, representing the colour of real fruit juice.

Refractive index and SSC showed slightly confusing results. In case of orange syrups both parameters changed the same way (SSC from $60.06 \pm 0.05 \%$ to $66.81 \pm 0.1 \%$, refractive index from $1.4410 \pm 0.0001$ to $1.4549 \pm 0.0002$ ), they increased with increasing sugar content as expected. Surprisingly, raspberry syrups did not follow any rules. R_575_33 had the lowest sugar content but the second highest refractive index $(1.4477 \pm 0.0002)$ and SSC $(63.31 \pm 0.1 \%)$ while R_740_33 with the second highest sugar content had the lowest values of refractive index $(1.4423 \pm 0.0001)$ and SSC $(60.91 \pm 0.05 \%)$. It must be mentioned that in the case of R_575_33 syrup the sugar content was added as $57.5 \mathrm{~g} / 100 \mathrm{~mL}$ on the product label, but $75.7 \mathrm{~g} / 100 \mathrm{~mL}$ was given in the product description on the producer's website. Our results suggest the $75.7 \mathrm{~g} /$ $100 \mathrm{~mL}$ value was correct.

As expected from the earlier scientific literature (Juansah and Yulianti, 2016; Widodo et al., 2016) the magnitude of impedance increased with increasing sugar content (Fig. 8).

According to this, the second highest impedance values of sample R_575_33 showed, that its sugar content had to be higher than the value given on the product label. Chemical analysis is needed to check the real sugar content. In the case of orange flavoured samples O_757_33 had the highest impedance values, while those of O_790_33 were slightly lower despite the higher sugar content. What was worth noticing, O_757_33 is the only sample without any stabilizers, colorants, flavourings, or preservatives. O_600_33 contains E445 and E415 (xanthan gum) as stabilizer and has higher impedance values than O_740_33 with higher sugar content and E445 and E414 as stabilizer. These observations confirmed the definite effect of additives on the physical properties of squashes.

\section{CONCLUSIONS}

Our results showed that variations in fruit and sugar content had a definite effect on the physical properties of squashes. Although colour characteristics was defined mostly by the colorant added to the squash, the other parameters were influenced by the amount of added sugar and used fruit juice. Sweetener content decreased viscosity, refractive index, SSC values and 
impedance magnitude of the tested products. Changes in the fruit composition of syrups could influence viscosity, refractive index, and SSC values but the magnitude of impedance showed little changes for all samples. The characteristics of squashes containing only raspberry or orange juice and different sugar content did not follow any trends, which emphasized that additives had a significant effect on the physical properties. Based on our results, those syrups can be considered most consumer friendly; those that most closely resemble traditional syrups, contain only fruit juice and sugar.

\section{REFERENCES}

Al-Dabbas, M.M. and Al-Qudsi, J.M. (2012). Effect of partial replacement of sucrose with the artificial sweetener sucralose on the physico-chemical, sensory, microbial characteristics, and final cost saving of orange nectar. The International Food Research Journal, 19(2): 679-683.

Ashurst, P.R., Hargitt, P., and Palmer, F. (2017). Soft drink and fruit juice problems solved 2nd edition Woodhead Publishing.

Ghafari, Z., Hojjatoleslamy, M., Shokrani, R., and Shariaty, M.A. (2013). Use of date syrup as a sweetener in non-alcoholic beer: sensory and rheological assessment. Journal of Microbiology, Biotechnology and Food Sciences, 3(2): 182-184.

Juansah, J. and Yulianti, W. (2016). Studies on electrical behavior of glucose using impedance spectroscopy. IOP Conference Series: Earth and Environmental Science, 31: 012039. https://doi.org/10.1088/17551315/31/1/012039.

Korzenszky, P., Géczi, G., and Kaszab, T. (2020). Comparing microwave and convective heat treatment methods by applying color parameters of wine. Progress in Agricultural Engineering Sciences, 16(S1): 105-113. https://doi.org/10.1556/446.2020.10011.

Pongsawatmanit, R., Yakard, N., and Suwonsichon, T. (2011). Effect of xanthan gum on the quality of syrup thickened by modified starch during heating and storage Kasetsart University. Natural Science, 45: 128-135.

Tang, B., He, Y., Liu, J., Zhang, J., Li, J., Zhou, J., Ye, Y., Wang, J., and Wang, X. (2019). Kinetic investigation into $\mathrm{pH}$-dependent color of anthocyanin and its sensing performance. Dyes and Pigments, 170, November 2019: 107643, ISSN 0143-7208. https://doi.org/10.1016/j.dyepig.2019.107643.

Torskangerpoll, K. and Andersen, Ø.M. (2005). Colour stability of anthocyanins in aqueous solutions at various $\mathrm{pH}$ values. Food Chemistry, 89: 427-440.

Vozáry, E., Ignácz, K., and Gillay, B. (2020). Dielectrical properties of Hungarian acacia honeys. Progress in Agricultural Engineering Sciences, 16(S1): 131-139 https://doi.org/10.1556/446.2020.10014.

Widodo, C.S., Santosa, D.R., and Juswono, U.P. (2016). Double layer impedance analysis on the electrical impedance measurement of solution using a parallel plate. Journal of Environmental Engineering Sustainable Technology, 3(1): 65-69.

Open Access. This is an open-access article distributed under the terms of the Creative Commons Attribution 4.0 International License (https://creativecommons.org/licenses/by/4.0/), which permits unrestricted use, distribution, and reproduction in any medium, provided the original author and source are credited, a link to the CC License is provided, and changes - if any - are indicated. (SID_1) 